\title{
Hollow CoFe-layered double hydroxide polyhedrons for highly efficient $\mathrm{CO}_{2}$ electrolysis
}

\author{
Miaosen Yang ${ }^{1,2}$, Jiaqiang Sun ${ }^{3}$, Yongji Qin ${ }^{4}$, Hui Yang ${ }^{5 *}$, Shusheng Zhang ${ }^{6}$, Xijun Liu $^{7 *}$ and Jun Luo ${ }^{4}$
}

Over the past several decades, the utilization of fossil fuels is responsible for mainly excessive atmospheric carbon dioxide $\left(\mathrm{CO}_{2}\right)$ [1-3]. Increased concentration of $\mathrm{CO}_{2}$ contributes to the major portion of the critical issues faced worldwide, such as global warming and drastic changes in climate. Therefore, it is imperative to develop an alternative technology that is capable of providing an efficient and sustainable pathway to target the neutralization of $\mathrm{CO}_{2}$ level in the atmosphere. In this regard, both the photoreduction and electroreduction of $\mathrm{CO}_{2}$ powered by renewable energy to value-added chemicals are eco-friendly and promising approaches for the integrated utilization of $\mathrm{CO}_{2}$ [4-11]. Till date, the precious metal catalysts have been used to catalyze $\mathrm{CO}_{2}$ reduction reaction $\left(\mathrm{CO}_{2} \mathrm{RR}\right)$; nonetheless, their high cost and low earth-abundance significantly impede their wide applications [12-15]. Therefore, various alternative nanostructured catalysts through engineering strategies are highly desirable to boost $\mathrm{CO}_{2} \mathrm{RR}$ performance. Among these catalysts, hollow and porous structures, possessing unique advantages such as low density, large specific surface area, and low diffusion resistance, have been developed to efficiently enhance the catalytic performance [16-19]. This is attributed to the fact that their hierarchical porous structures can significantly enhance the diffusion of reactants with small diffusion blockage and short diffusion pathway [20,21].

In particular, hollow structured layered double hydroxides (LDHs) have emerged as potentially promising catalyst candidates, owing to their unique tunable architecture, compositional flexibility, low manufacturing cost, and ease of scale-up [22,23]. However, previous reports on hollow structured LDHs mainly demonstrated their use in the oxygen evolution reaction (OER) and oxygen reduction reaction (ORR) for water splitting and other reactions [24-27]. For the $\mathrm{CO}_{2} \mathrm{RR}$, hollow structured LDHs have been only established and successfully used as the photocatalysts [28-30] to capture solar energy in the presence of water vapor and light excitation, and the type of metal cations in $\mathrm{LDH}$ nanosheets strongly influenced the product of $\mathrm{CO}_{2}$ photoreduction. However, to the best of our knowledge, the application of hollow structured LDHs for the electroreduction of $\mathrm{CO}_{2}$ has not been reported till date, which is due to their severe hydrogen evolution reaction (HER) [31,32]. In general, LDHs are composed of $\mathrm{M}-\mathrm{OH}$ layers containing octahedrally coordinated $\mathrm{M} 1$ and $\mathrm{M} 2$ cations with hydroxyl-terminated lamellae [33,34]. Thus, LDHs offer a lower barrier for producing $\mathrm{H}_{2}$, rather than that for $\mathrm{CO}_{2}$ electroreduction.

Ionic liquids (ILs), an environmentally friendly media with low volatility and high ionic conductivity, have attracted significant research attention as novel electrolytes in the $\mathrm{CO}_{2} \mathrm{RR}$ field $[35,36]$. This is attributed to the fact that IL electrolyte can benefit the ionic conductivity and accelerate the electron transport. Moreover, fluorine-functionalized ILs exhibit strong interaction with $\mathrm{CO}_{2}$, which facilitates the chemisorption of $\mathrm{CO}_{2}$ followed by its conversion to $\mathrm{CO}_{2}{ }^{--}$intermediates, eventually inhibiting HER and effectively improving the electroreduction reaction $[37,38]$. Motivated by the above-mentioned advantages, a CoFe-LDH hollow polyhedron (denoted as CoFe-LDH/HP) electrode/IL electrolyte system was innovatively constructed in this study for the electroreduction of $\mathrm{CO}_{2}$. The as-prepared CoFe-LDH/HP catalyst exhibited a Faradaic efficiency (FE) of $86 \% \pm 3 \%$ at a moderate applied potential of $-0.9 \mathrm{~V} v s$. reversible hydrogen electrode (RHE) for $\mathrm{CO}$ production in the $[\mathrm{Bmim}] \mathrm{BF}_{4}$ IL-water electrolyte system (4 wt\% water). Moreover, $\mathrm{CoFe}-\mathrm{LDH} / \mathrm{HP}$ could constantly produce $\mathrm{CO}$ for more than $30 \mathrm{~h}$ with an $\mathrm{FE}$ of greater than $85 \%$, indicating its favorable stability. Experimental analyses evidenced that the unique architecture could provide more exposed active sites and faster $\mathrm{CO}_{2}$ RR kinetics, both of which are beneficial for the electrocatalytic improvement. Theoretical calculations further confirmed that the Co-O-Fe moiety in CoFe-LDH/HP not only stabilizes the key intermediate $(* \mathrm{COOH})$, but also decreases the corresponding activation barrier.

The CoFe-LDH/HP electrocatalysts were synthesized by in situ etching of self-templated metal-organic frameworks (MOFs) to form hollow structures with simultaneous generation of LDHs, according to the procedure mentioned in our previous reports $[39,40]$ and the schematic illustration of the preparation process is shown in Fig. 1a (see Supplementary information for

\footnotetext{
${ }^{1}$ School of Chemical Engineering, Northeast Electric Power University, Jilin 132012, China

${ }^{2}$ Nanchang Institute of Technology, Nanchang 330044, China

${ }^{3}$ State Key Laboratory of Coal Conversion, Institute of Coal Chemistry, Chinese Academy of Sciences, Taiyuan 030001, China

${ }^{4}$ Institute for New Energy Materials and Low-Carbon Technologies, Tianjin Key Lab for Photoelectric Materials \& Devices, School of Materials Science and Engineering, Tianjin University of Technology, Tianjin 300384, China

${ }^{5}$ School of Materials Science and Engineering, Tianjin University of Technology, Tianjin 300384, China

${ }^{6}$ College of Chemistry, Zhengzhou University, Zhengzhou 450000, China

${ }^{7}$ MOE Key Laboratory of New Processing Technology for Non-Ferrous Metals and Materials, and Guangxi Key Laboratory of Processing for Non-Ferrous Metals and Featured Materials, School of Physical Science and Technology, Guangxi University, Nanning 530004, China

* Corresponding authors (emails: 383151026@qq.com (Qin Y); y.hui1021@tjut.edu.cn (Yang H); xjliu@tjut.edu.cn (Liu X))
} 
a



ZIF-67
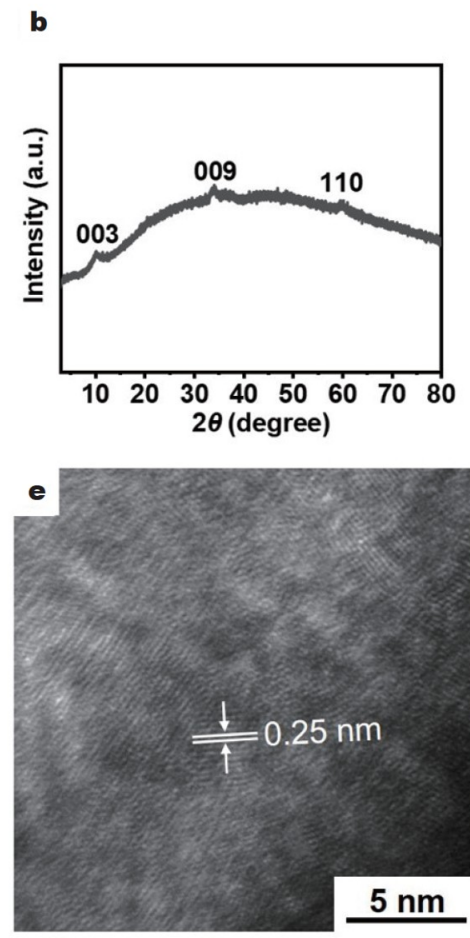
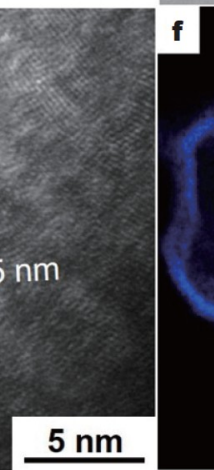

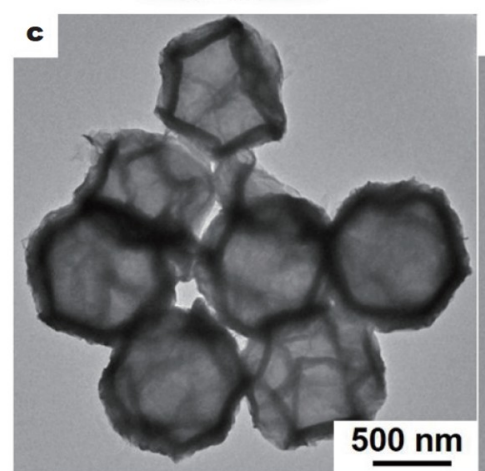

d


Cobalt nitrate
Iron nitrate

Transformation
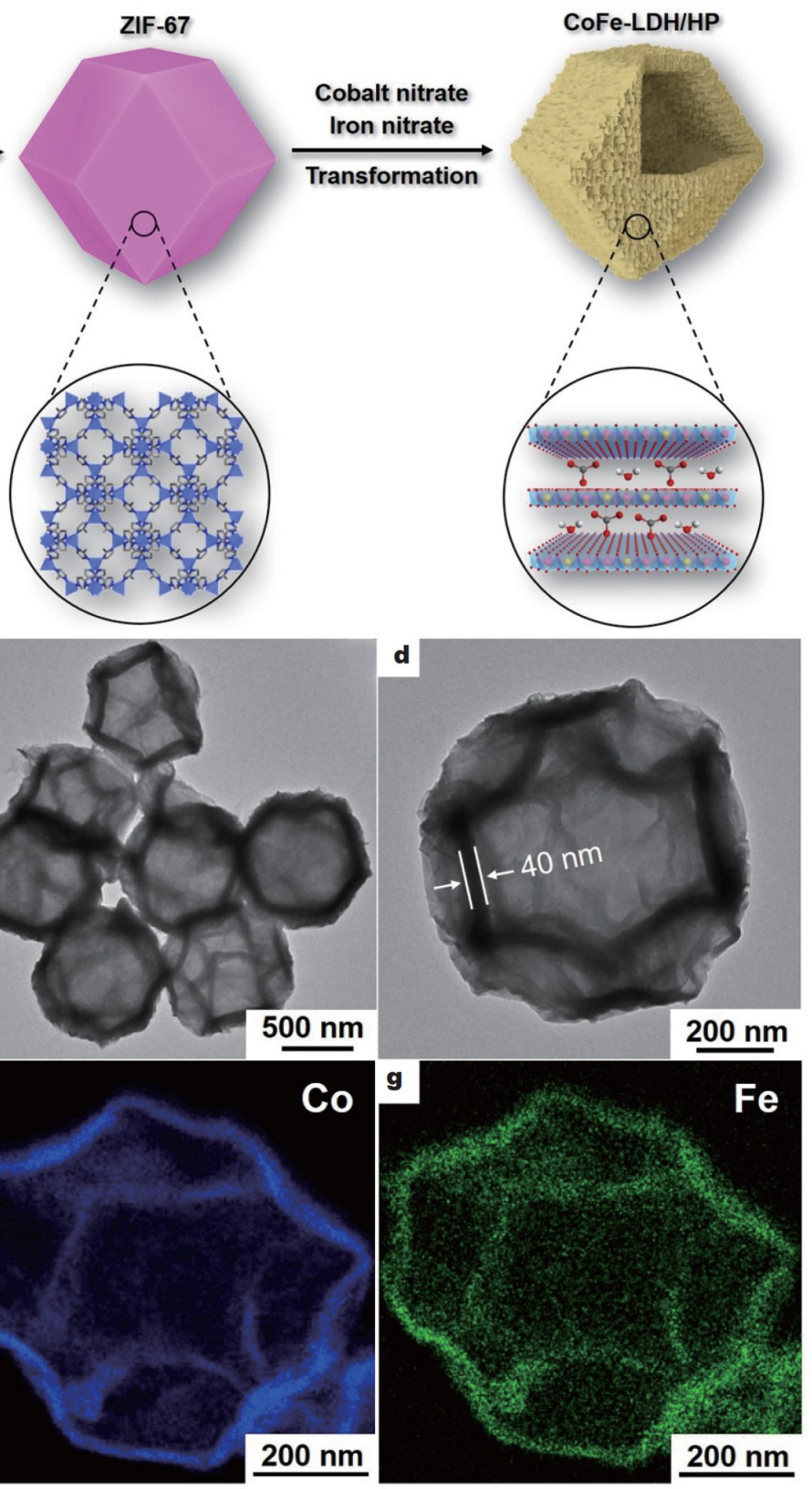

Figure 1 Synthesis and characterization: (a) Schematic illustration of the synthesis procedure of CoFe-LDH/HP, (b) XRD pattern, (c, d) TEM images, (e) HRTEM image, and (f, g) EDX elemental mapping images of CoFe-LDH/HP.

more details). Moreover, the reference sample of CoFe LDH sheet powder (namely CoFe-LDH/SP) was prepared via a facile hydrothermal method (Figs S1 and S2). The crystalline structure of the as-obtained $\mathrm{CoFe}-\mathrm{LDH} / \mathrm{HP}$ was characterized by X-ray diffraction (XRD) and the correponding patterns are shown in Fig. 1b. The diffraction peaks at $10.2^{\circ}, 34.1^{\circ}$, and $60.2^{\circ}$ are ascribed to the (003), (009), and (110) facets of CoFe LDH structure (JCPDS No. 89-0460). Fig. 1c exhibits the transmission electron microscopy (TEM) image of CoFe-LDH/HP, showing its morphological characteristics. Notably, several dispersed polyhedron nanoparticles with the hollow structure are observed from the different contrast in this image. The size of the CoFe$\mathrm{LDH} / \mathrm{HP}$ nanoparticle is estimated to be $600 \mathrm{~nm}$ with the shell thickness of $\sim 40 \mathrm{~nm}$ as shown in Fig. 1 d.
High-resolution TEM (HRTEM) image reveals the lattice fringes with an interplanar distance of $0.25 \mathrm{~nm}$, which is indexed to the $d$-spacing of the (009) plane of CoFe LDH (Fig. 1e), further confirming the formation of the CoFe-LDH in these HP nanoparticles. High-angle annular dark-field scanning TEM (HAADF-STEM) and the corresponding energy-dispersive Xray spectroscopy (EDX) mapping images were recorded to confirm the composition of the CoFe-LDH/HP nanoparticles (Fig. 1f, g). A homogeneous spatial distribution of Co and $\mathrm{Fe}$ was observed over a single nanoparticle. Moreover, some regions exhibit the significant concentration of $\mathrm{Co}$ and $\mathrm{Fe}$, indicating the presence of eight thick shells for the hollow nanoparticle, further confirming the structure nature of HPs.

To further confirm the chemical states of CoFe-LDH/HP, X- 
ray photoelectron spectroscopy (XPS) was utilized. In the highresolution Co $2 \mathrm{p}$ and Fe $2 \mathrm{p}$ spectra, Co $2 \mathrm{p}_{1 / 2}$ and Co $2 \mathrm{p}_{3 / 2}$ peaks were observed at 798.5 and $782.5 \mathrm{eV}$, respectively. [41,42] The fitting peaks at 799 and $783.5 \mathrm{eV}$ correspond to the Co $2 \mathrm{p}_{1 / 2}$ and Co $2 \mathrm{p}_{3 / 2}$ signals of $\mathrm{Co}^{3+}$ of $\mathrm{Co}-\mathrm{O}$ bonds in $\mathrm{CoFe}-\mathrm{LDH} / \mathrm{HP}$ (Fig. 2a), because some $\mathrm{Co}^{2+}$ was oxidized to $\mathrm{Co}^{3+}$ by the dissolved $\mathrm{O}_{2}$ and $\mathrm{NO}_{3}{ }^{-}$ions in the solution. The $\mathrm{Fe} 2 \mathrm{p}_{1 / 2}$ peak was observed at $724.5 \mathrm{eV}$ and deconvoluted into two peaks corresponding to the $\mathrm{Fe}^{2+}$ and $\mathrm{Fe}^{3+}$ of $\mathrm{Fe}-\mathrm{O}$ bonds [41,42] in $\mathrm{CoFe}-$ LDH/HP (Fig. 2b). Some shoulder peaks corresponding to the satellite peaks of main peaks are also present. The co-existence of the redox pairs of $\mathrm{Co}^{2+} / \mathrm{Co}^{3+}$ and $\mathrm{Fe}^{2+} / \mathrm{Fe}^{3+}$ confirmed the $\mathrm{LDH}$ construction in CoFe-LDH/HP [39,40].

The electrocatalytic $\mathrm{CO}_{2}$ performance of the obtained CoFe$\mathrm{LDH} / \mathrm{HP}$ was evaluated in a typical three-electrode setup with $\mathrm{CO}_{2}$-saturated $[\mathrm{Bmim}] \mathrm{BF}_{4}-\mathrm{H}_{2} \mathrm{O}$ electrolyte (4 wt $\%$ water), as previously reported by our group [43]. Moreover, the $\mathrm{CO}_{2} \mathrm{RR}$ activity of CoFe-LDH/SP was measured for comparative analysis. All potentials were reported with respect to the RHE in this study, and each current density was normalized by the geometric area of the electrode. Fig. 3a exhibits the linear sweep voltammetry (LSV) curves, presenting that the CoFe-LDH/HP electrode shows a higher reduction current density of $-12.6 \mathrm{~mA} \mathrm{~cm}^{-2}$ at $-0.9 \mathrm{~V}$ vs. RHE compared with the CoFeLDH/SP counterpart, indicating better electrocatalytic activity for these HP CoFe-LDHs. The CoFe-LDH/HP achieved the current density of $10 \mathrm{~mA} \mathrm{~cm}{ }^{-2}$ at a potential of $-0.85 \mathrm{~V} v s$. RHE (an overpotential of $0.74 \mathrm{~V}$ ), which is $100 \mathrm{mV}$ lower than that for $\mathrm{CoFe}-\mathrm{LDH} / \mathrm{SP}$. Compared with Ar-saturated electrolyte (Fig. S3), the higher current density achieved in the $\mathrm{CO}_{2}$-saturated case reveals that $\mathrm{CO}_{2} \mathrm{RR}$ electrolysis severely suppresses the competitive HER. Furthermore, the $\mathrm{CO}_{2} \mathrm{RR}$ performance of the $\mathrm{CoFe}-\mathrm{LDH} / \mathrm{HP}$ and $\mathrm{CoFe}-\mathrm{LDH} / \mathrm{SP}$ electrode in $0.1 \mathrm{~mol} \mathrm{~L}^{-1}$ $\mathrm{KHCO}_{3}$ solution (Fig. S4) was also investigated in this study. Clearly, CoFe-LDH/HP showed a superior selectivity with a high $\mathrm{FE} \geq 89 \%$ observed for $\mathrm{H}_{2}$ production in the potential range, thus further confirming that the ILs are essential for achieving efficient $\mathrm{CO}_{2} \mathrm{RR}$ and play a key role in producing $\mathrm{CO}$. In contrast, for CoFe-LDH/SP in $0.1 \mathrm{~mol} \mathrm{~L}^{-1} \mathrm{KHCO}_{3}$, the $\mathrm{FE}$ of $\mathrm{CO}_{2} \mathrm{RR}$ corresponds to the production of nearly 100-percentage of $\mathrm{H}_{2}$ without the formation of $\mathrm{CO}$ product, indicating $\mathrm{CoFe}-\mathrm{LDH} / \mathrm{SP}$ served as a better HER catalyst in aqueous solution. It confirmed the uniqueness and superiority of this HP structure. These results also demonstrate that the $\mathrm{CoFe}-\mathrm{LDH} / \mathrm{HP}$ cathode and the IL $\left(\left[\mathrm{Bmim}_{\mathrm{BmF}}\right)\right.$ constitute an excellent combination for pro- ducing $\mathrm{CO}$ from electrochemical reduction of $\mathrm{CO}_{2}$. As discussed above, both $\mathrm{CoFe}-\mathrm{LDH} / \mathrm{HP}$ cathodes and IL $\left([\mathrm{Bmim}] \mathrm{BF}_{4}\right)$ electrolytes are crucial for the high yield of CO.

Furthermore, gas chromatography (GC) and ${ }^{1} \mathrm{H}$ nuclear magnetic resonance (NMR) spectrometry were employed for the quantitative analysis of the $\mathrm{CO}_{2} \mathrm{RR}$ products after electrolysis for $2 \mathrm{~h}$ at each working potential. Noteworthily, no liquid product was detected (Fig. S5). Fig. 3b shows the dependence of FE for $\mathrm{CO}$ selectivity on the applied potentials for both $\mathrm{CoFe}-\mathrm{LDH} / \mathrm{HP}$ and $\mathrm{CoFe}-\mathrm{LDH} / \mathrm{SP}$. At a low applied potential of $-0.6 \mathrm{~V} v s$. $\mathrm{RHE}$, an $\mathrm{FE}$ of $41 \% \pm 4 \%$ for CO production was observed over the $\mathrm{CoFe}-\mathrm{LDH} / \mathrm{HP}$ electrode. It further increased as the potential became more negative, and the maximum $\mathrm{FE}\left(\mathrm{FE}_{\max }\right)$ of $86 \%$ $\pm 3 \%$ was achieved at $-0.9 \mathrm{~V} v$ s. RHE. This performance is comparable to the recently reported best value achieved using transition metal/noble metal-based electrocatalysts (Table S1), such as $\mathrm{Co}-\mathrm{N}-\mathrm{Ni}$ bimetallic sites supported on $\mathrm{N}$-doped porous carbon (96.4\% at $-0.58 \mathrm{~V}$ vs. RHE) [44]; $\mathrm{Ag}_{1}-\mathrm{N}_{3}$ anchored on porous concave $\mathrm{N}$-doped carbon (95\% at $-0.37 \mathrm{~V}$ vs. RHE) [45] in aqueous solution, and $\mathrm{Mo}_{2} \mathrm{C}(90 \%$ at $-2.24 \mathrm{~V}$ vs. saturated calomel electrode (SCE)) [46] in IL electrolyte. In contrast, for the $\mathrm{CoFe}-\mathrm{LDH} / \mathrm{SP}$ reference, the $\mathrm{FE}_{\max }$ of the $\mathrm{CO}$ production was $32 \% \pm 3 \%$ and this value is significantly less than that of $\mathrm{CoFe}-\mathrm{LDH} / \mathrm{HP}$. This contrast between the two electrodes with the HP and sheet powder morphology, respectively, clearly indicates that $\mathrm{CoFe}-\mathrm{LDH} / \mathrm{HP}$ serves as a better $\mathrm{CO}_{2} \mathrm{RR}$ catalyst, corresponding to the fact that HP structure provides increased number of the catalytically active sites, thereby promoting the $\mathrm{CO}_{2} \mathrm{RR}$ performance. It further confirms the unique structural feature of $\mathrm{HP}$ and its superiority in $\mathrm{CO}_{2} \mathrm{RR}$ toward $\mathrm{CO}$ production for CoFe-LDH/HP. To confirm this viewpoint, electrochemically active surface areas of the two electrodes were systematically investigated by the double-layer capacitance $\left(C_{\mathrm{dl}}\right)$ method $[43,47]$. The calculated $C_{\mathrm{dl}}$ of the CoFe-LDH/HP was $24 \mathrm{mF} \mathrm{cm}^{-2}$, approximately double of that for the CoFe-LDH/SP counterpart $\left(11 \mathrm{mF} \mathrm{cm}^{-2}\right.$ ) (Fig. $3 \mathrm{c}$ ), which confirms the exposure of an increased number of catalytically active sites in CoFe$\mathrm{LDH} / \mathrm{HP}$, and thus, promoted the electroreduction activity. Fig. 3d shows the volumetric $\mathrm{CO}_{2}$ adsorption results for $\mathrm{CoFe}-$ $\mathrm{LDH} / \mathrm{HP}$ and CoFe-LDH/SP, which demonstrate the enhancement of $\mathrm{CO}_{2}$ adsorption capacity on $\mathrm{CoFe}-\mathrm{LDH} / \mathrm{HP}$. This favors the $\mathrm{CO}_{2} \mathrm{RR}$, indicating that the $\mathrm{CO}_{2}$ adsorption is the prerequisite behavior before the $\mathrm{CO}_{2}$ reduction. Furthermore, $\mathrm{CoFe}-\mathrm{LDH} / \mathrm{HP}$ also showed a higher selectivity toward $\mathrm{CO}_{2}$ molecules compared with $\mathrm{N}_{2}$ molecules (Fig. S6). Moreover, the
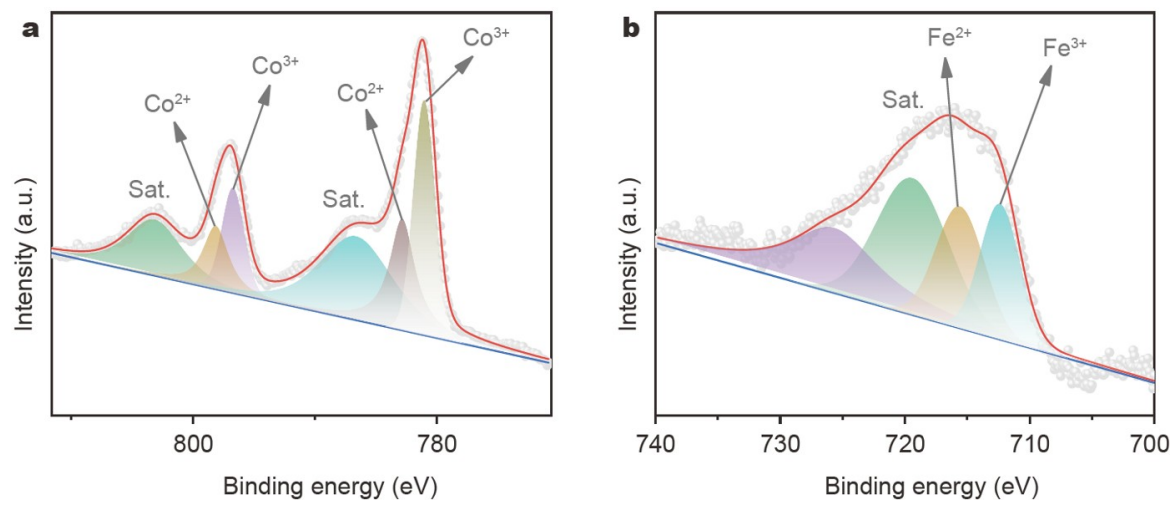

Figure 2 XPS analysis of CoFe-LDH/HP. (a, b) HRXPS spectra of Co 2p and Fe 2p. 

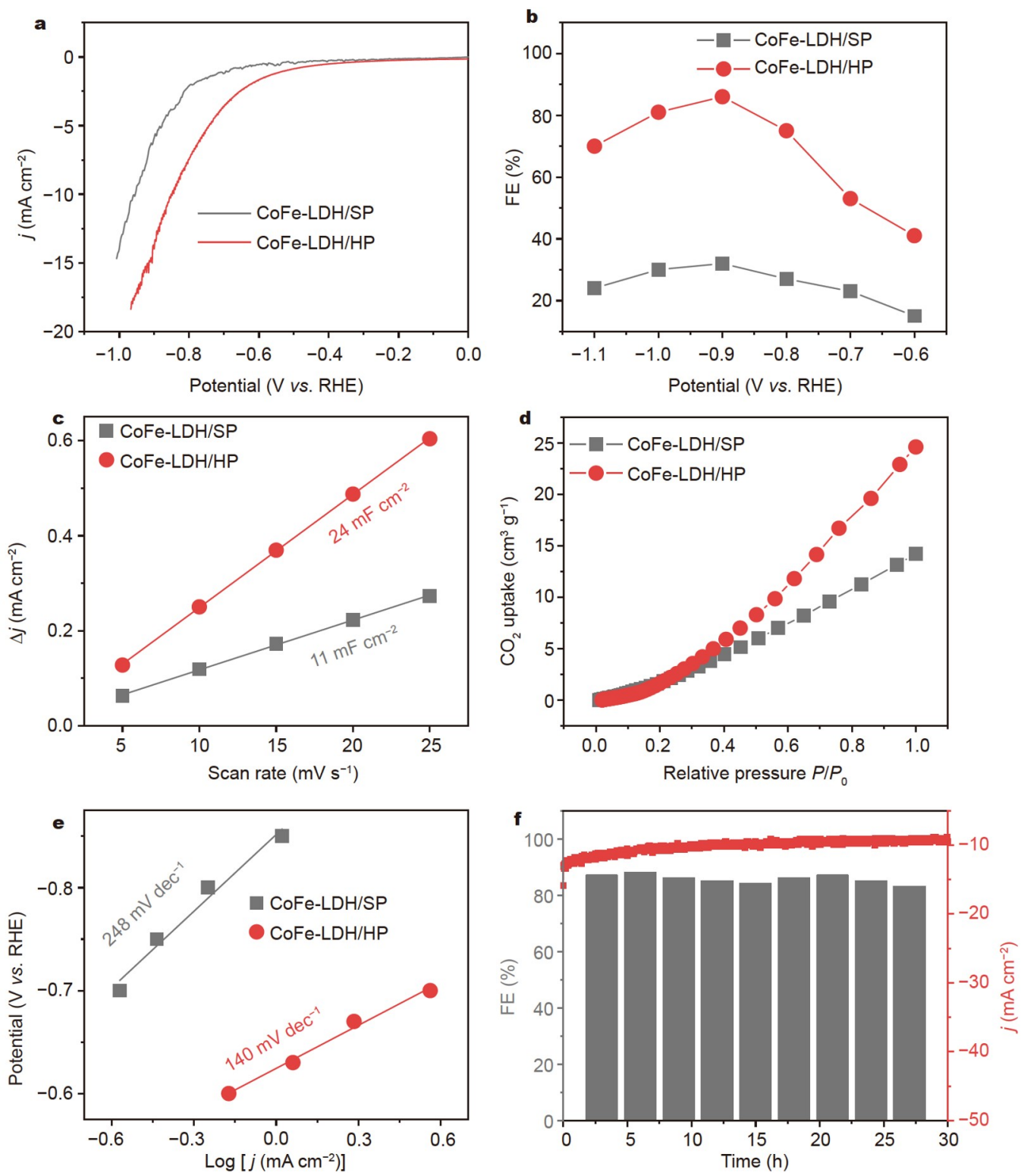

Figure $3 \mathrm{CO}_{2} \mathrm{RR}$ performance of $\mathrm{CoFe}-\mathrm{LDH} / \mathrm{HP}$ in a $\mathrm{CO}_{2}$-saturated $[\mathrm{Bmim}] \mathrm{BF}_{4}-\mathrm{H}_{2} \mathrm{O}$ electrolyte. (a) LSV curves at a scan rate of $10 \mathrm{mV} \mathrm{s}^{-1}$, (b) Faradaic efficiencies for $\mathrm{CO}$ at various applied potentials, (c) plots of charging current density differences versus scan rates, (d) $\mathrm{CO}_{2}$ adsorption isotherms, (e) Tafel slopes, and (f) stability test at $-0.9 \mathrm{~V} v s$. RHE and the corresponding FE variation for CO production.

IL electrolyte with fluorine benefits the ionic conductivity and interaction with $\mathrm{CO}_{2}$ [35-38], which facilitates the activation and the conversion of $\mathrm{CO}_{2}$ to $\mathrm{CO}_{2}{ }^{--}$intermediates and eventually leads to the effective improvement in the electroreduction reaction. The IL $[\mathrm{Bmim}] \mathrm{BF}_{4}$ containing fluorine shows strong interaction with $\mathrm{CO}_{2}$; therefore, the IL can serve as both robust electrolyte and $\mathrm{CO}_{2}$ activation promoter. Furthermore, chemical calculations [39] were performed to confirm the strong interaction in the intermediates formed between the cation of the IL and $\mathrm{CO}_{2}$ after receiving one electron.

In order to further disclose the kinetic mechanism for the enhanced $\mathrm{CO}_{2} \mathrm{RR}$ performance on both catalysts, Tafel slope analysis was carried out and shown in Fig. 3e. The CoFe-LDH/ HP exhibited a Tafel slope of $140 \mathrm{mV} \mathrm{dec}{ }^{-1}$, which is obviously lower than that of CoFe-LDH/SP $\left(248 \mathrm{mV} \mathrm{dec}^{-1}\right)$, manifesting faster $\mathrm{CO}_{2} \mathrm{RR}$ kinetics on $\mathrm{CoFe}-\mathrm{LDH} / \mathrm{HP}$. Nyquist plots further evidenced such a rapid electron transfer process (Fig. S7), which clearly showed that $\mathrm{CoFe}-\mathrm{LDH} / \mathrm{HP}$ had the lower interfacial charge-transfer resistance than CoFe-LDH/SP. Further, the obtained Tafel slope of CoFe-LDH/HP is close to a theoretical value $\left(118 \mathrm{mV} \mathrm{dec}^{-1}\right)$, which indicates that the first single-electron transfer from $\mathrm{CO}_{2}$ to produce ${ }^{*} \mathrm{COOH}$ moiety is the ratedetermining step (RDS) for the $\mathrm{CO}_{2} \mathrm{RR}$ on $\mathrm{CoFe}-\mathrm{LDH} / \mathrm{HP}$ $[48,49]$.

The stability under long-term electrolysis was also examined for evaluating the $\mathrm{CO}_{2}$ reduction performance (Fig. 3f). The current density of CoFe-LDH/HP was relatively stable at $-0.9 \mathrm{~V}$ $v s$. RHE even after $30 \mathrm{~h}$. Notably, the corresponding FE for CO production remained persistently greater than $85 \%$ during the electrocatalysis. To the best of our knowledge, in an aqueous 

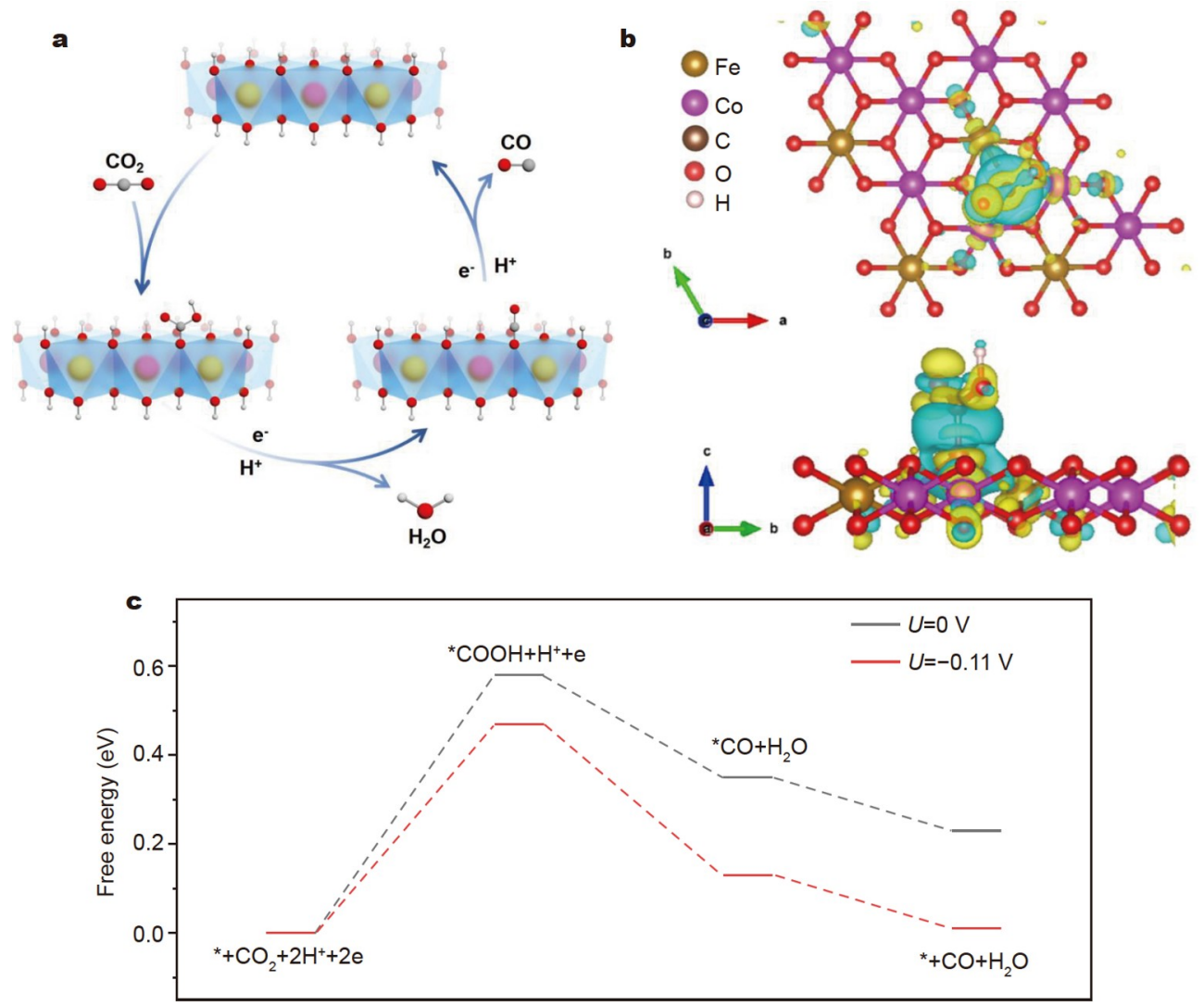

Reaction coordinate

Figure 4 DFT calculations: (a) a possible reaction pathway for $\mathrm{CO}_{2} \mathrm{RR}$ to $\mathrm{CO}$ on CoFe-LDH/HP, (b) differential charge diagrams, and (c) free energy profiles of $\mathrm{CO}_{2} \mathrm{RR}$ to $\mathrm{CO}$

solution, the CoFe-LDH/HP-based catalysts have been reported to be only applied in OER [25-27] and HER [31,32] in the literature. Moreover, herein, CoFe-LDH/HP after the 30-h electrolysis was further characterized and the TEM image clearly showed that CoFe-LDH/HP still maintained the HP morphology (Fig. S8). Furthermore, the XPS analysis of $\mathrm{CoFe}-\mathrm{LDH} / \mathrm{HP}$ confirmed a negligible change for the samples before and after the long-term electrolysis, as shown in Fig. S9, indicating good structural stability of $\mathrm{CoFe}-\mathrm{LDH} / \mathrm{HP}$. The above-mentioned electrochemical results confirmed that the designed CoFe-LDH/ $\mathrm{HP}$ catalyst simultaneously owns the high-activity for $\mathrm{CO}_{2} \mathrm{RR}$, excellent selectivity toward $\mathrm{CO}$, and good durability.

Based on the above-mentioned results and the previously reported studies [48,49], the mechanism for $\mathrm{CO}_{2}$ electroreduction to $\mathrm{CO}$ on the $\mathrm{CoFe}-\mathrm{LDH} / \mathrm{HP}$ electrode was proposed (Fig. 4a). The overall process proceeds as follows: initially, the $\mathrm{CO}_{2}$ molecule adsorbs on the $\mathrm{O}$ atom binding with $\mathrm{Co}$ and $\mathrm{Fe}$ of CoFe-LDH/HP surface and converts to $* \mathrm{CO}_{2}$, and then couples with a proton and electron to form ${ }^{*} \mathrm{COOH}$ intermediate and this step is identified as the RDS. Finally, the ${ }^{*} \mathrm{COOH}$ intermediate leaves off $\mathrm{H}_{2} \mathrm{O}$ to produce $\mathrm{CO}$.

In order to further provide mechanistic insights into the promoted $\mathrm{CO}_{2} \mathrm{RR}$ activity, density-functional-theory (DFT) calculations were performed to obtain the differential charge density and the Gibbs free energy profile of $\mathrm{CoFe}-\mathrm{LDH} / \mathrm{HP}$ and analyze the kinetics of elementary steps in the $\mathrm{CO}_{2} \mathrm{RR}$. The differential charge density of $\mathrm{Co}-\mathrm{O}-\mathrm{Fe}$ bonds in $\mathrm{CoFe}-\mathrm{LDH} / \mathrm{HP}$
(Fig. 4b) reveals that the charges accumulate around $\mathrm{Co}-\mathrm{O}-\mathrm{Fe}$ bonds and the electrons exchange between the $* \mathrm{COOH}$ and $\mathrm{Co}-$ $\mathrm{O}-\mathrm{Fe}$ is notable, indicating that $\mathrm{CoFe}-\mathrm{LDH} / \mathrm{HP}$ favors the stabilization of $* \mathrm{COOH}$ intermediate. From the free energy diagrams (Fig. 4c), the * $\mathrm{COOH}$ formation was the RDS on CoFeLDH surface, showing a free energy change of $0.56 \mathrm{eV}$, in line with Tafel slope analysis. When an extra potential was applied, the RDS energy barrier decreased, indicating an energeticfavorable pathway proceeded on $\mathrm{CoFe}-\mathrm{LDH}$ to form $\mathrm{CO}$ product. Furthermore, the free energy change of $\mathrm{CoFe}-\mathrm{LDH} / \mathrm{HP}$ for the HER was calculated to be $-0.18 \mathrm{eV}$ (Fig. S10), which is much lower than that for the $\mathrm{CO}_{2} \mathrm{RR}$, further indicating the key role of the usage of ILs-based electrolyte. Therefore, the relatively low free-energy barrier for the formation of key ${ }^{*} \mathrm{COOH}$ species, the large specific surface area from the hollow structure, and the strong chemisorption of $\mathrm{CO}_{2}$ facilitated by IL confirm the superior $\mathrm{CO}_{2} \mathrm{RR}$ performance over $\mathrm{CoFe}-\mathrm{LDH} / \mathrm{HP}$.

In this study, an active and robust electrocatalyst composed of CoFe LDH HPs was first reported towards $\mathrm{CO}_{2} \mathrm{RR}$ in IL electrolyte. It exhibited an improved performance toward $\mathrm{CO}_{2} \mathrm{RR}$ with a maximum CO FE of $86 \% \pm 3 \%$ at $-0.9 \mathrm{~V} v$ s. RHE and promising durability $(30 \mathrm{~h})$. Systematic characterizations demonstrated that such a unique architecture could expose more electrocatalytic active sites and promote interfacial charge/mass transfer, simultaneously. Theoretical calculations further reveal that the Co-O-Fe moiety not only favors the stabilization of the key $* \mathrm{COOH}$ intermediate, but also owns a small activation 
barrier for the RDS. This attempt presented herein sheds a bright light on the development of LDH HPs for $\mathrm{CO}_{2}$ fixation, and other electrocatalytic processes such as water splitting, $\mathrm{CO}$ reduction, and nitrogen reduction.

\section{Received 16 August 2021; accepted 3 November 2021; published online 13 December 2021}

1 Zheng $\mathrm{Y}$, Vasileff A, Zhou X, et al. Understanding the roadmap for electrochemical reduction of $\mathrm{CO}_{2}$ to multi-carbon oxygenates and hydrocarbons on copper-based catalysts. J Am Chem Soc, 2019, 141: 7646-7659

2 Yang $\mathrm{H}$, Han N, Deng J, et al. Selective $\mathrm{CO}_{2}$ reduction on 2D mesoporous Bi nanosheets. Adv Energy Mater, 2018, 8: 1801536

3 Gao $\mathrm{T}$, Xie $\mathrm{T}$, Han N, et al. Electronic structure engineering of 2D carbon nanosheets by evolutionary nitrogen modulation for synergizing $\mathrm{CO}_{2}$ electroreduction. ACS Appl Energy Mater, 2019, 2: 3151-3159

4 Wang L, Chen W, Zhang D, et al. Surface strategies for catalytic $\mathrm{CO}_{2}$ reduction: From two-dimensional materials to nanoclusters to single atoms. Chem Soc Rev, 2019, 48: 5310-5349

5 Yang C, Wang Y, Qian L, et al. Heterogeneous electrocatalysts for $\mathrm{CO}_{2}$ reduction. ACS Appl Energy Mater, 2021, 4: 1034-1044

6 Wang X, Chen Z, Zhao X, et al. Regulation of coordination number over single Co sites: Triggering the efficient electroreduction of $\mathrm{CO}_{2}$. Angew Chem Int Ed, 2018, 57: 1944-1948

7 Ji S, Qu Y, Wang T, et al. Rare-earth single erbium atoms for enhanced photocatalytic $\mathrm{CO}_{2}$ reduction. Angew Chem Int Ed, 2020, 59: 1065110657

$8 \mathrm{Li}$ Y. Hybrid atomic layers based electrocatalyst converts waste $\mathrm{CO}_{2}$ into liquid fuel. Sci China Mater, 2016, 59: 1-3

9 Li Y. Photosynthetic conversion of $\mathrm{CO}_{2}$ to acetic acid by an inorganicbiological hybrid system. Sci China Mater, 2016, 59: 93-94

10 Ji Y, Shi Y, Liu C, et al. Plasma-regulated $\mathrm{N}$-doped carbon nanotube arrays for efficient electrosynthesis of syngas with a wide $\mathrm{CO} / \mathrm{H}_{2}$ ratio. Sci China Mater, 2020, 63: 2351-2357

11 Yang D, Wang G, Wang X. Photo- and thermo-coupled electrocatalysis in carbon dioxide and methane conversion. Sci China Mater, 2019, 62: 1369-1373

12 Cai Z, Zhang Y, Zhao Y, et al. Selectivity regulation of $\mathrm{CO}_{2}$ electroreduction through contact interface engineering on superwetting $\mathrm{Cu}$ nanoarray electrodes. Nano Res, 2019, 12: 345-349

13 Zhou Y, Zhou R, Zhu X, et al. Mesoporous PdAg nanospheres for stable electrochemical $\mathrm{CO}_{2}$ reduction to formate. Adv Mater, 2020, 32: 2000992

14 Pan $\mathrm{Y}$, Lin $\mathrm{R}$, Chen $\mathrm{Y}$, et al. Design of single-atom Co- $\mathrm{N}_{5}$ catalytic site: A robust electrocatalyst for $\mathrm{CO}_{2}$ reduction with nearly $100 \% \mathrm{CO}$ selectivity and remarkable stability. J Am Chem Soc, 2018, 140: 42184221

15 Yang H, Wu Y, Li G, et al. Scalable production of efficient single-atom copper decorated carbon membranes for $\mathrm{CO}_{2}$ electroreduction to methanol. J Am Chem Soc, 2019, 141: 12717-12723

16 Zhang P, Wang S, Guan BY, et al. Fabrication of CdS hierarchical multi-cavity hollow particles for efficient visible light $\mathrm{CO}_{2}$ reduction. Energy Environ Sci, 2019, 12: 164-168

17 Li D, Liu T, Yan Z, et al. MOF-derived $\mathrm{Cu}_{2} \mathrm{O} / \mathrm{Cu}$ nanospheres anchored in nitrogen-doped hollow porous carbon framework for increasing the selectivity and activity of electrochemical $\mathrm{CO}_{2}$-to-formate conversion. ACS Appl Mater Interfaces, 2020, 12: 7030-7037

18 Tan $\mathrm{D}$, Lee $\mathrm{W}$, Kim YE, et al. $\mathrm{SnO}_{2} / \mathrm{ZnO}$ composite hollow nanofiber electrocatalyst for efficient $\mathrm{CO}_{2}$ reduction to formate. ACS Sustain Chem Eng, 2020, 8: 10639-10645

19 Huo $\mathrm{H}$, Liu D, Feng $\mathrm{H}$, et al. Double-shelled $\mathrm{Cu}_{2} \mathrm{O} / \mathrm{MnO}_{x}$ mesoporous hollow structure for $\mathrm{CO}_{2}$ photoreduction with enhanced stability and activity. Nanoscale, 2020, 12: 13912-13917

20 Qin Y, Han X, Li Y, et al. Hollow mesoporous metal-organic frameworks with enhanced diffusion for highly efficient catalysis. ACS Catal, 2020, 10: 5973-5978

21 Lin X, Wang S, Tu W, et al. MOF-derived hierarchical hollow spheres composed of carbon-confined $\mathrm{Ni}$ nanoparticles for efficient $\mathrm{CO}_{2}$ methanation. Catal Sci Technol, 2019, 9: 731-738

22 Li P, Wang M, Duan X, et al. Boosting oxygen evolution of singleatomic ruthenium through electronic coupling with cobalt-iron layered double hydroxides. Nat Commun, 2019, 10: 1711

23 Cai M, Liu Q, Xue Z, et al. Constructing 2D MOFs from 2D LDHs: A highly efficient and durable electrocatalyst for water oxidation. J Mater Chem A, 2020, 8: 190-195

24 Chen S, Duan J, Jaroniec M, et al. Three-dimensional N-doped graphene hydrogel/NiCo double hydroxide electrocatalysts for highly efficient oxygen evolution. Angew Chem Int Ed, 2013, 52: 13567-13570

$25 \mathrm{Gu} \mathrm{H}$, Shi G, Chen HC, et al. Strong catalyst-support interactions in electrochemical oxygen evolution on $\mathrm{Ni}-\mathrm{Fe}$ layered double hydroxide. ACS Energy Lett, 2020, 5: 3185-3194

26 Fagiolari L, Bini M, Costantino F, et al. Iridium-doped nanosized Zn-Al layered double hydroxides as efficient water oxidation catalysts. ACS Appl Mater Interfaces, 2020, 12: 32736-32745

27 Jung E, Kim JK, Choi H, et al. Aqueous-phase synthesis of layered double hydroxide nanoplates as catalysts for the oxygen evolution reaction. Dalton Trans, 2018, 47: 17342-17348

28 Xiong $\mathrm{X}$, Zhao $\mathrm{Y}$, Shi R, et al. Selective photocatalytic $\mathrm{CO}_{2}$ reduction over Zn-based layered double hydroxides containing tri or tetravalent metals. Sci Bull, 2020, 65: 987-994

29 Dewangan N, Hui WM, Jayaprakash S, et al. Recent progress on layered double hydroxide (LDH) derived metal-based catalysts for $\mathrm{CO}_{2}$ conversion to valuable chemicals. Catal Today, 2020, 356: 490-513

30 Chen G, Gao R, Zhao Y, et al. Alumina-supported CoFe alloy catalysts derived from layered-double-hydroxide nanosheets for efficient photothermal $\mathrm{CO}_{2}$ hydrogenation to hydrocarbons. Adv Mater, 2018, 30: 1704663

31 Jia $\mathrm{X}$, Zhao $\mathrm{Y}$, Chen $\mathrm{G}$, et al. $\mathrm{Ni}_{3} \mathrm{FeN}$ nanoparticles derived from ultrathin NiFe-layered double hydroxide nanosheets: An efficient overall water splitting electrocatalyst. Adv Energy Mater, 2016, 6: 1502585

32 Yang $\mathrm{H}$, Chen $\mathrm{Z}$, Guo P, et al. B-doping-induced amorphization of LDH for large-current-density hydrogen evolution reaction. Appl Catal B-Environ, 2020, 261: 118240

33 Mohapatra L, Parida K. A review on the recent progress, challenges and perspective of layered double hydroxides as promising photocatalysts. J Mater Chem A, 2016, 4: 10744-10766

34 Tran NV, Tieu AK, Zhu H. First-principles molecular dynamics study on the surface chemistry and nanotribological properties of $\mathrm{MgAl}$ layered double hydroxides. Nanoscale, 2021, 13: 5014-5025

35 Zhang Z, Song J, Han B. Catalytic transformation of lignocellulose into chemicals and fuel products in ionic liquids. Chem Rev, 2017, 117: 6834-6880

36 Ren $\mathrm{W}$, Tan $\mathrm{X}$, Chen $\mathrm{X}$, et al. Confinement of ionic liquids at single-Nisites boost electroreduction of $\mathrm{CO}_{2}$ in aqueous electrolytes. ACS Catal, 2020, 10: 13171-13178

37 Sun $\mathrm{X}, \mathrm{Lu} \mathrm{L}, \mathrm{Zhu} \mathrm{Q}$, et al. MoP nanoparticles supported on indiumdoped porous carbon: Outstanding catalysts for highly efficient $\mathrm{CO}_{2}$ electroreduction. Angew Chem Int Ed, 2018, 57: 2427-2431

38 Huan TN, Simon P, Rousse G, et al. Porous dendritic copper: an electrocatalyst for highly selective $\mathrm{CO}_{2}$ reduction to formate in water/ ionic liquid electrolyte. Chem Sci, 2017, 8: 742-747

39 Qin Y, Wang F, Shang J, et al. Ternary NiCoFe-layered double hydroxide hollow polyhedrons as highly efficient electrocatalysts for oxygen evolution reaction. J Energy Chem, 2020, 43: 104-107

40 Qin Y, Wang B, Qiu Y, et al. Multi-shelled hollow layered double hydroxides with enhanced performance for the oxygen evolution reaction. Chem Commun, 2021, 57: 2752-2755

41 Yang $\mathrm{Y}, \mathrm{Ou} \mathrm{Y}$, Yang $\mathrm{Y}$, et al. Modulated transition metal-oxygen covalency in the octahedral sites of CoFe layered double hydroxides with vanadium doping leading to highly efficient electrocatalysts. Nanoscale, 2019, 11: 23296-23303

$42 \mathrm{Xu} \mathrm{H}$, Yuan Y, Liao Y, et al. $\left[\mathrm{MoS}_{4}\right]^{2-}$ cluster bridges in Co-Fe layered double hydroxides for mercury uptake from S-Hg mixed flue gas. Environ Sci Technol, 2017, 51: 10109-10116

43 Liu X, Yang H, He J, et al. Highly active, durable ultrathin $\mathrm{MoTe}_{2}$ layers for the electroreduction of $\mathrm{CO}_{2}$ to $\mathrm{CH}_{4}$. Small, 2018, 14: 1704049 
44 Sui R, Pei J, Fang J, et al. Engineering Ag- $\mathrm{N}_{x}$ single-atom sites on porous concave $\mathrm{N}$-doped carbon for boosting $\mathrm{CO}_{2}$ electroreduction. ACS Appl Mater Interfaces, 2021, 13: 17736-17744

45 Pei J, Wang T, Sui R, et al. N-bridged Co-N-Ni: New bimetallic sites for promoting electrochemical $\mathrm{CO}_{2}$ reduction. Energy Environ Sci, 2021, 14: 3019-3028

46 Attanayake NH, Banjade HR, Thenuwara AC, et al. Electrocatalytic $\mathrm{CO}_{2}$ reduction on earth abundant $2 \mathrm{D} \mathrm{Mo}_{2} \mathrm{C}$ and $\mathrm{Ti}_{3} \mathrm{C}_{2}$ MXenes. Chem Commun, 2021, 57: 1675-1678

47 Gao S, Lin Y, Jiao X, et al. Partially oxidized atomic cobalt layers for carbon dioxide electroreduction to liquid fuel. Nature, 2016, 529: 68-71

$48 \mathrm{Xu}$ J, Lai S, Hu M, et al. Semimetal $1 \mathrm{H}-\mathrm{SnS}_{2}$ enables high-efficiency electroreduction of $\mathrm{CO}_{2}$ to CO. Small Methods, 2020, 4: 2000567

49 Hsieh YC, Senanayake SD, Zhang Y, et al. Effect of chloride anions on the synthesis and enhanced catalytic activity of silver nanocoral electrodes for $\mathrm{CO}_{2}$ electroreduction. ACS Catal, 2015, 5: 5349-5356

Acknowledgements This work was supported by the Research Fund of State Key Laboratory for Marine Corrosion and Protection of Luoyang Ship Material Research Institute (LSMRI) (KF190411), and Tianjin Natural Science Foundation (18JCQNJC77100). The authors also acknowledge Beijing PARATERA Tech CO., Ltd. for providing HPC resources that have contributed to the research results reported in this paper.

Author contributions Liu X and Qin Y designed the project. Yang M and Sun J performed the main experiments and Yang $\mathrm{H}$ wrote this manuscript. Zhang $\mathrm{S}$ and Luo J helped to analyze the data, discussed the results and contributed to the theoretical analysis. All authors contributed to the general discussion.

Conflict of interest The authors declare that they have no conflict of interest.

Supplementary information Experimental details and supporting data are available in the online version of the paper.

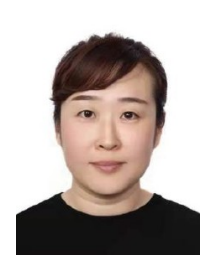

Miaosen Yang received her PhD degree in chemical engineering and technology from Beijing University of Chemical Technology in 2012. Her current scientific interests focus on the design, preparation and application of inorganic functional materials and organic-inorganic composite materials.

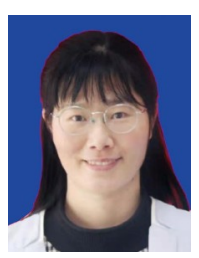

Hui Yang received her $\mathrm{PhD}$ degree in materials science in 2013 from the South China University of Technology (SCUT). She currently conducts scientific research at Tianjin University of Technology. Her current research mainly focuses on the synthesis of advanced nanomaterials for catalytic applications.



Xijun Liu received his $\mathrm{PhD}$ degree from the College of Science, Beijing University of Chemical Technology in 2014. His current scientific interests focus on nanomaterials, heterogeneous catalysis, and materials design for catalysts and energy conversion/storage.

\section{钴铁层状双金属氢氧化物空心多面体用于高效电催 化二氧化碳还原}

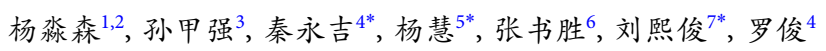

摘要 可再生能源驱动电催化二氧化碳还原制备高附加值化学燃料, 是一种实现二氧化碳资源化的有效途径. 以金属有机骨架 $(\mathrm{MOF})$ 为模 板制备的层状双金属氢氧化物空心多面体已成为当前电催化领域的热 门材料. 然而, 该类材料的高析氢活性严重阻碍了其在电催化二氧化碳 还原中的应用. 基于此, 本文报道了一种在离子液体电解液中可高效稳 定电催化二氧化碳还原的钴铁层状双金属氢氧化物空心多面体 $(\mathrm{CoFe}$ $\mathrm{LDH} / \mathrm{HP})$, 其最大法拉第转换效率可达 $86 \% \pm 3 \%(-0.9 \mathrm{~V}$ 相对于可逆氢 电极), 且可连续电解 $30 \mathrm{~h}$. 实验结果表明此 CoFe LDH/HP因其独特的 空心结构可暴露更多的活性位点, 从而具有更快的电催化二氧化碳还 原动力学; 理论计算表明 $\mathrm{CoFe} \mathrm{LDH} / \mathrm{HP}$ 中 Co-O-Fe键有利于稳定关键 中间体 $(* \mathrm{COOH})$ 并降低相应的活化势垒. 本研究可为其他层状双金属 氢氧化物用于二氧化碳固定的设计提供参考. 